\title{
Criação e Cuidado: Perspectivas bíblicas
}

\author{
Haroldo Reimer
}

$\mathrm{Na}$ linguagem bíblica, tanto a criação como espaço de vida e cultura quanto o lugar dos humanos neste espaço da vida é articulado em termos de fé. A linguagem da fé abre o texto das Sagradas Escrituras. A frase "no princípio criou Deus os céus e a terra", em Gênesis 1,1, expressa a dimensão de que o Deus de Israel é o criador, colocando-se a afirmação como contestação a outras expressões religiosas do entorno cultural de Israel, nas quais também era reivindicado o epíteto de criador para a divindade local ou nacional.

$\mathrm{O}$ apontamento de fé em Gênesis 1,1 quer remeter para as origens últimas do espaço cultural entendido como criação. Aí a fé é articulada em linguagem mítica. Assim como os outros povos do entorno cultural do antigo Israel, o conjunto das relações sociais e suas legitimações religiosas é comunicado em forma de mito. As primeiras páginas da Bíblia estão perpassadas pela linguagem mítica. ${ }^{1}$ A estrutura de mundo e de tempo são concebidas como tendo suas estruturas fundamentais lançadas no momento primeiro do ato de criação.

\section{Criação original e continuada}

O que se expressa por meio da frase "no princípio criou Deus os céus e a terra", em Gênesis 1,1, se refere, em termos sistemáticos, à creatio pri-

\footnotetext{
${ }^{1}$ Sobre a relação entre Bíblia e mito, cf. meu texto "Mitologia e Bíblia", em: RICHTER REIMER, Ivoni e MATOS, Keila (eds.). Mitologia e literatura sagrada. Goiânia: Editora PUC Goiás, 2009, p. 11-38, com muitas indicações bibliográficas sobre a temática.
} 
$m a$, a "criação primeira" de Deus, acontecida nas origens. Num tempo que não pode ser nominado em termos cronológicos mais exatos, mas deve ser entendido como momento mítico originário e indeterminado, 'criação' é um espaço conquistado em meio ao caos existente das "águas do abismo". Este espaço é chamado de 'terra' (Gn 1,2). Esta terra é adjetivada por meio da expressão hebraica tohu wabohu para designar o estado de coisas antes da ação criadora de Deus. "Vazia e sem forma" é a tradução que a Bíblia de Almeida atribui a esta expressão, o que se apresenta de forma similar em outras traduções, dando com isso vazão à noção de uma "criação a partir do nada", o que, contudo, não corresponde ao sentido do texto hebraico. Traduzir por "desolação e vazio", provavelmente, corresponde melhor ao original hebraico, pois em analogia a Jeremias 4,22 trata-se de um espaço devastado, caótico, sem a ordenação que possibilita a vida. $\mathrm{O}$ ato de criar reorganiza um caos pré-existente. Neste sentido, as águas caóticas são elemento préexistente, o que inviabiliza em si a noção de criação a partir do nada. ${ }^{2}$ A criação como ação de conquista em meio às águas caóticas é tema recorrente na literatura antiga, especialmente do mundo mesopotâmico.

A ação criadora de Deus nesta creatio prima é vinculada com o termo ruah elohim (Gn 1,2), uma expressão que usualmente é traduzida por "Espírito de Deus", "espírito de Deus", associando-se assim a ação criadora com a direta atividade divina. Esta tradução, contudo, é muito discutida, propondo-se nas diversas traduções da Bíblia expressões bem diferentes como "vento tempestuoso", "vento forte", etc. ${ }^{3}$

Segundo o testemunho de fé bíblico, o espaço ordenado e criado em meio ao ambiente caótico é o lugar em que é alocado o ser humano, o adam. O termo adam designa o ser humano originário, em sua acepção de protótipo mítico. Na linguagem bíblica, há maneiras distintas de falar da criação do ser humano. Em Gênesis 1,27 se afirma que o adam é "criado" como "imagem e semelhança" do Criador. A diferenciação em masculino e feminino confere a ambos, homem e mulher, igual e simultânea dignidade. Em Gênesis 2,7 é dito que o adam é "formado" a partir da adamah, termo que pode ser melhor traduzido por "terra cultivável" ao invés de "argila", como propõem algumas traduções. Esta relação evidencia, em sentido bíblico, uma íntima conexão entre os humanos e a terra. $\mathrm{O}$ humano emerge a partir do corpo da própria terra. Na língua latina, esta relação quase umbilical pode ser expressa por meio do trocadilho humanus - humus: o humano foi formado a partir do

\footnotetext{
${ }^{2}$ Ver a respeito, SIMKINS, Ronald A. Criador e criação. A natureza na mundividência do antigo Israel. Tradução de Jaime A. Clasen. Petrópolis: Vozes, 2004.

${ }^{3}$ Cf. RIBEIRO, Osvaldo Luiz. Vento Tempestuoso: um ensaio sobre a tradução e a interpretação de Gn 1, 2 à luz de Jr 4. Fragmentos de Cultura, Goiânia, v. 12, n. 4, p. 573-598, 2002.
} 
húmus! O espírito vivificante transforma este "ser terroso' em "garganta vivente" ou, como se afirma em algumas traduções, em "alma vivente".

Neste espaço de vida, o ser humano criado ou formado por Deus recebe atribuições específicas, embora distintas. Destaque merece a dignificação por meio do conceito de "imagem e semelhança" com o Criador (Gn 1,26-28), uma noção que ao longo do tempo contribuiu para a formatação do conceito moderno de "dignidade humana". Segundo o texto bíblico, os humanos recebem atribuições ou mandatos que oscilam entre o domínio e o cuidado (Gn 1,28; 2,15), revelando-se aí tradições distintas na origem dos textos. Muita recepção tem recebido o mandato de "sujeitar e dominar" (Gn $1,28)$ em detrimento do binômio "cultivar e guardar" (Gn 2,15). Este último deve ser potencializado nas interpretações contemporâneas justamente em face das facetas dos desajustes ambientais, provavelmente em decorrência da forte intervenção humana no ambiente. ${ }^{4}$ No conjunto das atribuições conferidas ao Adam consta também o mandato da procriação por meio da expressão "crescei e multiplicai-vos" (Gn 1,28), o qual se justifica num tempo em que os homens tinham que dominar o ambiente para sobreviver, mas que deve ser relativizado atualmente quando a comunidade humana mundial aparenta se tornar uma ameaça ao ambiente.

$\mathrm{O}$ credo criacionista perpassa toda a Bíblia. Especial ressonância desta perspectiva de fé se encontra no Salmo 104, quando o autor do salmo enfatiza que o Espírito de Deus é a energia que vivifica e perpassa toda a criação. O salmista dá expressão do seu louvor dizendo: "Que variedade, Senhor, nas tuas obras! Todas com sabedoria as fizeste [...] Envias o teu Espírito, eles são criados, e assim renovas a face da terra" (S1 104.24,30). Deus e seu espírito vivificante (ruah) são entendidos como a base de manutenção desta criação.

A confissão de fé do povo de Israel, condensada num credo monoteísta típico daquela expressão religiosa, passa por releitura e ampliação de sentido no seio do movimento do cristianismo das origens, com influências em toda a história posterior. O Deus criador monoteísta dos hebreus, além de sua presença no mundo na forma da ruah, é reconhecido na vida, cruz e ressurreição de Jesus de Nazaré. Na Carta aos Colossenses se lê: "Ele [Cristo] é a imagem do Deus invisível, o primogênito de toda a criação; pois nele foram criadas todas as coisas, nos céus e sobre a terra, as visíveis e as invisíveis [...] Tudo foi criado por meio dele e para ele" $(\mathrm{Cl} 1,15-16)$. Com isso, o Deus criador é simultaneamente o redentor e o sustentador, três formas de ação do mesmo Deus.

\footnotetext{
${ }^{4}$ Sobre isso, ver REIMER, Haroldo. Bíblia e ecologia. São Paulo: Reflexão, 2010, p. 20-45.
} 
A tradição da igreja dos primeiros séculos amalgamou esta diversidade na unidade em palavras do Credo Apostólico: "Creio em Deus Pai, todo poderoso, criador dos céus e da terra." De modo especial ecoam as palavras de Martin Lutero em sua explicação do primeiro artigo do credo no Catecismo Menor: "Creio que Deus me criou junto com todas as criaturas, e me deu corpo e alma, olhos, ouvidos e todos os membros, inteligência e todos os sentidos, e ainda os conserva; além disso, me dá roupa, calçado, comida e bebida, casa e lar, família, terra, trabalho e todos os bens". Esta interpretação de Lutero já indica para a criação continuada.

Falar da 'criação de Deus', portanto, nos remete a um ponto nevrálgico da teologia judaico-cristã. Entende-se, reconhece-se, crê-se o mundo existente como obra criadora de Deus. 'Criação' remete à experiência da dádiva e da gratuidade divinas. Dizer 'criação' pressupõe a consciência da relação primordial entre Criador e criatura. A própria existência é vista como dádiva. E sendo Cristo o primogênito da criação, a própria criação é substancialmente dignificada por meio da encarnação de Deus em Cristo. A criação, o conjunto do mundo criado, portanto, é entendido como mistério e transparência para Deus. ${ }^{5}$ Especialmente por meio do Cristo encarnado, mas também pela ação do Espírito, Deus está presente na criação à espera do reconhecimento por parte dos filhos e filhas, suas criaturas, como bem expressa o apóstolo Paulo na sua Carta aos Romanos, na qual escreveu: "Toda a criação, a um só tempo, geme e suporta angústias até agora” (Rm 8,22).

Em perspectiva cristã, dizer também que Cristo é o Alfa e o Ômega significa afirmar que toda a criação e, portanto, toda a história [humana e natural] é vista em perspectiva teleológica, isto é, ela se encaminha para uma destinação última, que, em fé, é entendida como o tornar-se pleno do Reino de Deus, consumador e redentor. ${ }^{6}$

Um dado a ressaltar é que, apesar, da concepção da creatio prima, a criação enquanto espaço ordenado que possibilita a vida necessita de constante cuidado. Quando se lê a Bíblia de modo seqüencial ou sincrônico, esta dimensão aparece pela primeira vez na história do dilúvio em Gênesis 6-9. Segundo a cosmovisão dos antigos hebreus, em boa medida compartilhada com os povos do entorno cultural, especialmente da Mesopotâmia, a terra como espaço de vida e cultura está rodeada de águas. Estas águas, que no relato da criação aparecem como pré-existentes, foram ordenadas, isto é,

\footnotetext{
5 TAVARES, Sinivaldo S. Teologia da criação. Outro olhar - novas relações. Petrópolis: Vozes, 2010, p. 57-70 [A criação como mistério].

${ }^{6}$ Nesta concepção são muito impactantes as contribuições de Teihlard de Chardin. Cf. CHARDIN, T. Hino do universo; A missão sobre o mundo; Cristo na matéria; Três histórias no estilo de Benson; A potência espiritual da matéria. São Paulo: Paulus, 1994.
} 
afastadas, fazendo surgir separação entre as águas de cima e as águas de baixo, dando origem à terra habitável. Deus como senhor e mantenedor da criação pode reverter esta situação, abrindo as "fontes do abismo" e as "comportas dos céus" (Gn 8,2), originando o caos do dilúvio ou da antivida. Assim, a vida ordenada pela criação pode submergir novamente nas águas do caos. O Salmo 104,5-9 mostra de modo muito plástico como o Deus criador deve constantemente preservar a ordem do mundo criado a fim de manter afastados os perigos do caos e das trevas. Em Provérbios 30,4 há uma pergunta retórica que afirma: "quem encerrou as águas no manto?". Na linguagem sapiencial, a resposta almejada é que tal ação se deve ao cuidado constante do Deus criador.

De modo bastante elucidativo esta noção de terra como 'espaço criado' aparece também no livro de Jó, especialmente na parte final, na qual, sob a forma de uma teofania, Deus faz uma série de perguntas àquele Jó que somente buscava a esperada e supostamente devida recompensa de Deus por sua fidelidade: "Quem encerrou o mar com portas [...] e lhe disse: 'até aqui virás e não mais adiante, e aqui se quebrará o orgulho das tuas ondas?" (Jó $38,8.11)$. Novamente, em tom sapiencial, a resposta almejada é que tal tarefa faz parte das multifacetárias atividades cotidianas do Deus criador como requisito indispensável para a manutenção da ordem e vida da criação. ${ }^{7}$

Convém salientar que falar de 'criação' é falar em linguagem da fé; é discurso teológico ou fala confessional. Durante muito tempo, esta linguagem outorgou sentido e identidade a pessoas e comunidades. Em alguns momentos se chegou a construir uma visão cósmica da criação, projetando interrelacionalidade entre todos os elementos do mundo criado por Deus. Típico para isso são reflexões de Francisco de Assis, já no final da Idade Média.

Falar de 'criação' é utilizar-se de uma linguagem típica do chamado 'mundo pré-moderno', 'tradicional', no qual Deus ainda ocupa lugar de referência central. Em um mundo "emancipado" de Deus, como já o propunha o teólogo luterano Dietrich Bonhoeffer, e tantos outros teólogos depois dele, a exemplo de Jürgen Moltmann ${ }^{8}$ ou Hans Küng ${ }^{9}$, que trabalham sob influência do paradigma da secularização, falar de 'criação' significa assumir o risco do conflito. Significa assumir uma posição de resistência em face do

\footnotetext{
${ }^{7}$ Sobre isso, ver o capítulo "Complexa criação - uma leitura de Jó em perspectiva ecológica" no meu livro Bíblia e ecologia (op. cit.).

${ }^{8}$ MOLTMANN, Jürgen. Deus na criação. Doutrina ecológica de Deus. Tradução Haroldo Reimer. Petrópolis: Vozes, 1996; IDEM. Ciência e sabedoria. Um diálogo entre ciência natural e teologia. São Paulo: Loyola, 2007.

${ }^{9}$ KÜNG, Hans. O princípio de todas as coisas. Ciências naturais e religião. Petrópolis: Vozes, 2007.
} 
chamado 'mundo moderno', no qual Deus perdeu o seu lugar como referência e como presença. Em lugar de Deus como referente de centralidade, o ser humano foi ocupando este espaço central, passando a se construir gradativamente uma visão de mundo tendencialmente antropocêntrica. Com a afirmação do antropocentrismo no processo da Modernidade ocidental, a criação passa gradativamente a ser vista como natureza, passando o ser humano a se entender como sobreposto a ela por meio da razão instrumental. Dilemas entre religião e ciência demandam por respostas urgentes. ${ }^{10}$

\section{Paradigma moderno, ameaças à criação e nova visão ecológica}

O chamado paradigma de Modernidade trouxe consigo uma profunda ruptura em relação à cosmovisão tradicional. Embora amplos segmentos populacionais, também no mundo ocidental, continuassem imersos no paradigma antigo, o avanço da ciência e da filosofia crítica enquanto espaços autônomos em relação ao controle da Igreja possibilitaram uma mundivisão, na qual a natureza se tornou fundamentalmente uma reserva de recursos entendidos como em função das necessidades e dos desejos dos seres humanos. Muitos pensadores e cientistas contribuíram para moldar este novo conceito de natureza como espaço subordinado e externo ao ser humano, constantemente passível de subjugação e exploração. ${ }^{11}$ A racionalidade técnicocientífica acabou por gerar uma cisão entre homem e mundo (natureza), ocasionando a sobreposição hierárquica do homem em relação à natureza. ${ }^{12}$

A voracidade das necessidades e dos desejos humanos aumentou incrivelmente quando no século XVIII a humanidade atingiu numericamente o primeiro bilhão no mesmo compasso da revolução industrial capitaneada pela Inglaterra. A partir daí a demarcação geopolítica do mundo se tornou ainda mais crassa. O novo mundo, com exceção da América do Norte, deveria corresponder ainda mais à sua função de fornecedor de recursos naturais para a indústria européia, não importando os custos humanos e ambientais destes processos de exploração. Com isso, o capitalismo proporcionou uma acumulação de riquezas nunca dantes vista na história humana, deixando lamentáveis rastros de destruição ambiental e humana.

\footnotetext{
${ }^{10}$ BRAKEMEIER, Gottfried. Ciência ou religião: quem vai conduzir a história? São Leopoldo: Sinodal, 2006. Ver também as instigantes reflexões de TAVARES, op. cit.

${ }^{11}$ Sobre isso ver especialmente CAPRA, Fritjof. O Ponto de Mutação: a ciência, a sociedade e a cultura emergente. Tradução de Álvaro Cabral. São Paulo: Cultrix, 2006.

12 BULCAO, Marly. O Binômio natureza-cultura. A perspectiva de Gaston Bachelard. In: CESAR, Constança Marcondes (Ed.). Natureza, cultura e meio ambiente. Campinas: Editora Alínea, 2006, p. 27-34.
} 
A tecnociência possibilitou ainda mais a explosão demográfica, com diminuição da taxa de mortandade infantil, do aumento das possibilidades reprodutivas e com o prolongamento da média de idade da população. Com a industrialização crescente e a mecanização de processos produtivos, enormes fluxos migratórios do campo para a cidade formaram os grandes conglomerados urbanos, que passaram a sinalizar esta marcha do progresso e indicar de forma cada vez mais clara o descompasso em relação às condições de regeneração do ambiente.

Os impactos ambientais do crescimento humano se fazem perceber de forma cada vez mais clara, expressando-se em muitas manifestações fenomênicas de crise e desajustes ambientais. Ainda que a ciência e a técnica já estivessem em condições de frear as nefastas intervenções no ambiente, a taxa de degradação do ambiente natural tem aumentado acima da taxa de crescimento populacional. O homem retira da natureza matérias primas acima da capacidade de regeneração sistêmica da natureza. Estima-se que a taxa de extinção de espécies naturais cresce na mesma proporção do crescimento da população. A comunidade humana em seu conjunto se revela como sujeito ativo de uma lógica ecocida. ${ }^{13}$ Salvo algumas honráveis exceções, por onde passam, os humanos, na sua ânsia por vida, por pressões econômicas e fatores históricos, por satisfação de desejos limitados e de desejos ilimitados, interferem, destroem e poluem o ambiente. Desmatamento, desertificação do solo poluição dos mananciais são facetas de uma crise ambiental de proporções globais. Estes desajustes do ambiente vão gerando perceptíveis mudanças climáticas, às quais os humanos são chamados a se ajustar cada vez mais, demandando ciência e sabedoria.

Hoje se discute se as facetas da crise ou dos desajustes ambientais, tais como a chuva ácida, o aquecimento do planeta e os câmbios climáticos têm causas antrópicas ou não. Isto é, discute-se se o homem e sua forma de organização e de produção são responsáveis por tais fenômenos catastróficos ou se a própria natureza se organiza ciclicamente com efeitos nefastos sobre parte dos seres que ocupam o planeta. Nos grandes encontros internacionais tem prevalecido a tese da causa antrópica das crises ambientais. Embora contestada por alguns cientistas, esta tese situa as discussões atuais como conseqüência de um longo processo evolutivo e de expansão do ser humano sobre a terra. A evolução humana coloca em risco a própria humanidade e o ambiente como um todo, gerando incertezas quanto ao destino especialmente das gerações futuras.

${ }^{13}$ BOFF, Leonardo. A opção terra. A solução para a terra não cai do céu. Rio de Janeiro; São Paulo: Record, 2009. 
A partir da década de 1970, com a crise do petróleo, os alertas científicos começaram a ganhar eco na opinião pública. O documento "Nosso futuro comum", da Comissão Brundtland, talvez pela primeira vez na história, deu expressão à percepção de que os recursos naturais são finitos e que o desenvolvimento humano não pode se dar indefinidamente como um ininterrupto processo de assalto aos recursos do meio ambiente. A partir daí o conceito de "desenvolvimento sustentável" passou a ganhar espaço como forma de indicar um tipo de desenvolvimento, no qual o modo de organização da humanidade deve estar ajustado às condições do ambiente, possibilitando a regeneração sistêmica do próprio ecossitema. Com isso estavam lançadas as bases dos movimentos ambientais e do pensamento ecológico contemporâneos.

Os povos antigos ou tradicionais já haviam intuído ou reconhecido o que os contemporâneos agora insistem em dizer: a terra é um grande sistema vivo, é uma grande casa para todos os elementos da criação. Trata-se da 'hipótese gaia' que em época recente foi formulada por James Havelock, o qual acolheu impulsos de outros pensadores. Segundo esta 'hipótese gaia', as interferências exacerbadas numa parte deste grande sistema vivo repercutem sobre o todo. A terra é vista como um superorganismo vivo, no qual se pode verificar a interdependência entre os mais diferentes componentes, fenômeno expresso pelo conceito de 'panrelacionalidade'.

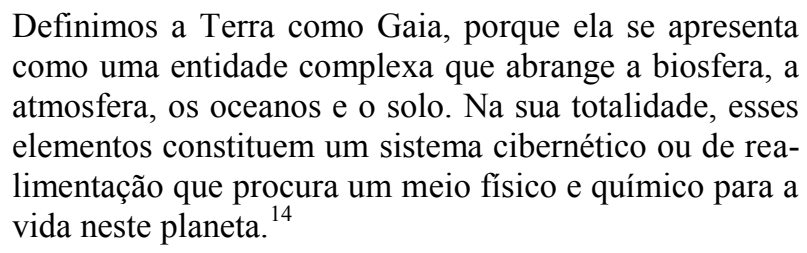

A emergência destes novos conceitos e novas formas de viver e pensar acabam por modificar o modo de ver e entender o mundo, a terra. Com a perspectiva da complexidade e das muitas probabilidades nas formas de relação, aquilo que no paradigma moderno era (é) chamado de 'natureza' passa a ser visto como 'meio ambiente' ou simplesmente 'ambiente'. Ambiente é o conjunto daquilo que envolve a forma de vida a partir da qual se expressam a percepção e a reflexão, isto é, a vida humana. No conceito 'meio ambiente', o ser humano não mais pode ser pensado em termos de ruptura e sobreposição hierárquica, mas de convivência e de interdependência com o

\footnotetext{
${ }^{14}$ LOVELOCK, James. Gaia. Um novo olhar sobre a vida na terra. Lisboa: Edições 70, 1989, p. 27; IDEM. As eras de Gaia. A biografia da nossa terra viva. São Paulo: Campus, 1991.
} 
próprio ambiente. Complexidade passou a ser termo necessário nas análises e discussões teóricas. A respeito disso Edgar Morin escreve:

\begin{abstract}
É preciso substituir um pensamento que separa por um pensamento que une, e essa ligação exige a substituição da causalidade unilinear e unidimensional por uma causalidade em círculo e multirreferencial, assim como a troca da rigidez da lógica clássica por uma dialógica capaz de conceber noções ao mesmo tempo complementares e antagônicas; que o conhecimento da integração das partes num todo seja completada pelo reconhecimento da integração do todo no interior das partes. ${ }^{15}$
\end{abstract}

Entender a terra como ambiente ou organismo vivo situa a mesma em outro patamar em termos de reflexão ética e teológica. Pode-se falar de certa reversão do paradigma moderno na relação para com a terra. Para transformar a terra em natureza passível de ser estudada, penetrada, explorada e transformada em mercadoria foi necessário, no processo de afirmação da Modernidade, retirar dela todos os seus atributos em termos de sacralidade. Hoje, diante das demandas dos desajustes do clima do planeta com suas conseqüências nefastas e as correspondentes exigências de cada vez mais adaptação da comunidade humana ao conjunto maior e em face da perspectiva de que a terra é um organismo vivo ressurge a possibilidade ética do respeito à vida. Isso tem se evidenciado em vários documentos recentes que tratam da questão, mas fica especialmente transparente na Carta da Terra, fruto de um longo processo de maturação, mas com redação decisiva no ano de 2000. Também a Carta dos Direitos da Terra, formulada na ONU em 2010 se situa nesta linha de pensamento. A Carta da Terra está estrutura em 4 princípios fundantes e 16 pontos referenciais do modo sustentável de vida. Os 4 princípios são: a) respeitar e cuidar da comunidade de vida; b) integridade ecológica; c) justiça social e ecológica; d) democracia, não violência e paz. ${ }^{16}$ Cada vez mais se impõe a percepção do planeta como uma grande "teia da vida". ${ }^{17}$

Muitas e multifacetadas são as contribuições que, apesar de grande insensibilidade ainda reinante, fazem emergir um novo paradigma de civilização. A emergência discursiva de comunidades da terra faz emergir novas

\footnotetext{
${ }^{15}$ Apud TAVARES, op. cit., p. 39. Ver também MORIN, Edgar. Ciência com consciência. Rio de Janeiro: Bertrand, 1995.

${ }^{16}$ BOFF, op. cit., p. 184-198.

${ }^{17}$ CAPRA, Fritjof. A teia da vida. Uma nova compreensão científica dos sistemas vivos. São Paulo: Cultrix, 1996.
} 
perspectivas. O ecofeminismo proporcionou riquíssimas reflexões. ${ }^{18}$ Especial destaque neste contexto merece a contribuição do judeu alemão Hans Jonas com sua obra $O$ princípio responsabilidade, originalmente publicada em 1979 e com muitos ecos e influências sobre discussões posteriores. ${ }^{19}$ A partir de uma "heurística do medo", no sentido de que "o saber origina-se daquilo contra o que devemos nos proteger" 20 , ele propõe revisitar e revisar os fundamentos éticos modernos, inserindo neles a reflexão sobre a cumulatividade do desenvolvimento científico e as conseqüências de longo alcance e das ações presentes no contexto de uma sociedade tecnocientífica, tendo em vista (também) a vida e os direitos das gerações futuras. Isso impõe uma lógica de responsabilidade, de sabedoria e de cuidado na relação dos humanos entre si e com ambiente vital. ${ }^{21}$

A situação da casa global evidencia crises evidentes. Remete a temores justificados. O medo não deve vencer a esperança, mas transformar as ameaças de fazer a travessia humana rumo à realização de si mesma e de um estágio superior de seu desenvolvimento. "É tempo de travessia; se não ousarmos fazê-la, teremos ficado, para sempre, à margem de nós mesmos" (Fernando Pessoa).

Neste processo de travessia e de construção de novas perspectivas hermenêuticas, um acesso com outro olhar também é salutar no processo de interpretação de textos bíblicos.

\section{Perspectivas bíblicas}

Nos trilhos desta travessia de interpretação ecológica de textos bíblicos, alguns passos podem ser delineados.

1 - Um dos primeiros passos nos trilhos de uma leitura ecológica dos textos bíblicos é o reconhecimento dos sinais da crise ambiental, especificamente aqueles derivados da ação humana sobre o ambiente. Aí se trata de um exercício de sensibilidade, que depende do nível de consciência de cada pessoa. Como Abraão, a pessoa deve estar aberta para a novidade e o chamado. Em termos teológicos, a constatação do apóstolo Paulo em sua Carta aos

\footnotetext{
${ }^{18}$ MIES, Mari; SHIVA, Vandana. Ökofeminismus: Beiträge zur Praxis und Theorie. Zürich: Rotpunkt-Verlage, 1995.

${ }^{19}$ JONAS, Hans. O principio responsabilidade. Rio de Janeiro: PUC; Contexto, 2006.

${ }^{20}$ JONAS, op. cit., p. 71.

${ }^{21}$ Ver também GLEISER, Marcelo. Criação imperfeita. Cosmo, vida e código da natureza. Rio de Janeiro: Record, 2009. Cf. também SOUZA, Waldir. "O princípio responsabilidade" em Hans Jonas. Um desafio para a bioética numa contínua transcendência. Atualidade Teológica, Rio de Janeiro, ano XIV, n. 35, p. 172-194, 2010.
} 
Romanos pode servir de alerta: "Toda a criação, a um só tempo, geme e suporta angústias até agora" $(8,23)$. É necessário interpretar os sinais dos tempos. A dimensão de "toda a criação" precisa estar mais presente na educação teológica continuada e no exercício da espiritualidade, com claros impactos nas ações do cotidiano. O hábito tem grande efeito pedagógico! $\mathrm{O}$ velho dualismo corpo-alma, com a negativa da corporeidade, e esta ainda associada ao feminino, ${ }^{22}$ precisa ser superado em prol de uma visão holística, integral do ser humano em sintonia e convivência com toda a criação.

2 - Em segundo lugar, trata-se de perceber-se a si mesmo como integrante de uma rede maior de relações de produção e consumo. Trata-se de perceber em que medida o ser humano como indivíduo ou como comunidade integrante de um todo maior contribui para aumentar ou diminuir o peso da pegada ecológica. ${ }^{23}$ Os humanos são seres de combustão. Alimentam-se de outras formas de vida para a própria manutenção. As intervenções, contudo, podem ser diferentemente moduladas. A "pegada humana" sobre o ambiente pode ser mais pesada ou mais leve. Depende do modo como se pisa. Há formas mais predatórias de organizar a vida em sociedade e há formas menos predatórias. No fundo depende do exercício de sabedoria. ${ }^{24}$ Pode começar com um simples ato de reciclagem, podendo culminar em ações mais efetivas na mudança de hábitos de consumo. Se o capitalismo, o agronegócio, etc. são o "satã do ambiente", os consumidores são clientes deste satã, acelerando a depredação.

3 - Em terceiro lugar, deve-se buscar fazer prevalecer o cuidado sobre o domínio. ${ }^{25}$ Trata-se de falar mais concretamente da dimensão da fé de que Deus é criador e cuidador da de toda a criação. Em consonância com este destino das origens, nós humanos também comungamos, em termos teológicos, do destino soteriológico de toda a criação. Com boa leitura do relato da criação em Gênesis podemos perceber que os seres humanos são criaturas juntamente com os demais elementos da criação. Todos os elos da criação têm dignidade própria. Segundo o relato bíblico, ao homem Deus conferiu dignidade especial de "imagem e semelhança". A mais profunda realização

\footnotetext{
${ }^{22}$ Ver a respeito GEBARA, Ivone. Teologia ecofeminista. Ensaio para repensar o conhecimento e a religião. São Paulo: Olho dágua, 1997 e a coletânea Fontes e caminhos ecofeministas. São Leopoldo: Cebi, 2002.

${ }^{23}$ DIAS, Genebaldo Freire. Pegada ecológica e sustentabilidade humana. São Paulo: Gaia, 2009.

${ }_{24}^{24}$ MURAD, Afonso. Aquele que passeia em nós. São Paulo: Paulinas, 2009.

${ }^{25}$ Aqui permanecem válidas e instigantes as reflexões de BOFF, Leonardo. Saber cuidar. Ética do humano, compaixão pela Terra. Petrópolis: Vozes, 1999.
} 
desta similaridade para com o criador é a imitação na misericórdia e no cuidado. Deus também atribuiu também responsabilidades aos humanos. Em lugar do binômio "dominar e sujeitar" (Gn 1,28) é necessário ressaltar cada vez mais a noção também profundamente bíblica de que o ser humano deve ser "mordomo da criação". Sua tarefa fundamental deve consistir em "cultivar e guardar" (Gn 2.15). O "cultivar" implica necessariamente em intervenção sobre o ambiente natural, produzindo ou retirando dele os elementos para suprir as necessidades e os desejos dos homens. Em habraico, o verbo traduzido por "cultivar" (abad) expressa a dimensão de "trabalho árduo", expressando, portanto, a noção de necessária e penosa intervenção no ambiente. O "guardar" (hebraico: shamar) é um exercício de responsabilidade e cuidado. Trata-se de um mandato que exige por parte da pessoa a sabedoria de perceber-se integrante do todo da criação com a tarefa de zelar para que a natureza, e com isso também a humanidade, se mantenha, para além do tempo presente, em suas próprias bases ecossistêmicas, estendendo-se como dádiva continuada do criador em favor das futuras gerações.

4 - Um quarto passo consiste em buscar superar a lógica sacrificial em prol da lógica do cuidado. O personagem bíblico Noé é emblemático e, de certa, em termos míticos, é o fundador da lógica sacrificial. Ao sair da arca, o primeiro gesto de Noé é um ato de respeito e reverência, que consiste em prestar culto a Deus por meio do holocausto de animais (Gn 8,20-22). O seu gesto, contudo, inaugura uma lógica de sacrifício: algum ser vivente da criação precisa ser sacrificado para agradar a Deus! O sacrifício de elementos da criação acabou se tornando quase um traço típico do paradigma da modernidade. A esta sina sacrificial há que se contrapor elementos bíblicos mais positivos e inspiradores. Na Bíblia há várias passagens na Bíblia em que a dimensão do cuidado dos humanos pela integridade da criação é destacada. Tais passagens devem ser garimpadas em meio ao todo das Escrituras. O grito profético em Oséias 6.8 ecoa neste sentido: "misericórdia quero e não sacrifícios". De especial beleza e sentido paradigmático se reveste o texto de Êxodo 23,10-11, no qual é proposto que ao homem legitimamente concedido cultivar a terra e recolher os frutos dela, constituindo nisto sua atividade de produção e intervenção no ambiente. O ritmo produtivo e explorador, no entanto, deve ser temporalmente limitado a seis anos, devendo o sétimo ano ser um tempo de "descanso sabático". O texto indica três finalidades desta norma: a) primeiramente é dito que a própria terra deve poder descansar. Isso é estranho ao modo de pensar 'moderno', nos qual se está acostumado com a idéia de que a terra deve somente servir para satisfação de nossas necessidades (e desejos); b) em segundo lugar, os pobres devem 
poder colher o que nascer por conta própria no sétimo ano, tendo uma provisão extra além de sua limitada alimentação usual; c) em terceiro, indica-se que os animais do campo devem poder comer do que sobrar. Explicitamente se inclui aí os animais do campo dentro de um ciclo ecológico. Três seres ameaçados em sua existência devem ser contemplados no modo de se organizar a vida em sociedade: a terra, os pobres e os animais. Isso é o que se pode chamar de uma "visão ecológica" da vida. Os interesses econômicos são limitados pela integridade da vida e da criação. Há ainda muitas outras passagens que podem ser "garimpadas" numa leitura ecológica da Bíblia. ${ }^{26}$

5 - Além do texto exemplar acima referido, na Bíblia há muitas recomendações para a observância de tempos de pausa que se articulam na lógica do chamado ritmo seis-sete. Este ritmo seis-sete marca a estrutura do tempo semanal de sete dias, sintonizado com o ciclo da lua. Ajustado para o ritmo de trabalho e pausa para os humanos e para a criação, estes textos que falam do descanso sabático (Ex 20,8-11) ou também do ano sabático (Ex 21,2-11; 23,10-11) remetem para a necessária observância de tempos de pausa, de shabbat, isto é, de uma cessação das atividades laborais em meio ao em meio ritmo produtivo para o cultivo do ócio. Isso é reconhecido como necessário para que os humanos, os animais e a terra possam tomar alento e regenerarse para a constância e saúde do ciclo de vida. ${ }^{27}$

6 - Outro passo importante nesta travessia da leitura ecológica da Bíblia é pensar toda a criação dentro do amplo projeto salvífico de Deus. Além da tarefa de zelador, cuidador ou mordomo da criação, o ser humano é constantemente chamado ao exercício da misericórdia. Há muitas narrativas da prática e do ensino de Jesus Cristo que podem ser aqui lembradas. ${ }^{28} \mathrm{~A}$ parábola do bom samaritano (Lc 10.25-37) se presta muito bem a essa indicação, obviamente com uma interpretação expansiva. A história é conhecida: um homem maltratado está deitado à beira do caminho. Duas pessoas passam e desviam do caminho. Um terceiro passante, "vendo-o, compadeceu-se dele" (v. 33). A interpretação extensiva, quase alegórica, consiste em substituir no texto o "homem ferido" por "natureza maltratada", ou, então, entender o homem ferido como extensão de 'criação'. Esta criação caída geme, em

\footnotetext{
${ }^{26}$ Para mais exemplos remete para o meu livro acima referido Bíblia e ecologia (2010).

${ }^{27}$ Aqui ainda permanecem atuais as reflexões esboçadas em REIMER, Haroldo; RICHTER REIMER, Ivoni. Tempos de graça. Jubileu e as tradições jubilares na Bíblia. São Leopoldo: Sinodal; Cebi; São Paulo: Paulus, 1999.

${ }^{28}$ Sobre as dimensões ecológicas no movimento de Jesus, cf. o livro de RICHTER REIMER, Ivoni. Terra e água na espiritualidade do movimento de Jesus. Contribuições para um mundo globalizado. Goiânia: PUC Goiás; São Leopoldo: Oikos, 2010.
} 
dores, em correntes de exploração humana, aguardando a redenção e a manifestação plena dos filhos de Deus. Assim, natureza e humanidade estão incluídas no plano redentor de Deus para toda a sua criação.

7 - Como elemento quase climático e catalizador de toda esta travessia da leitura ecológica da Bíblia pode-se indicar para o exercício do cuidado como forma de amar e ser amado. Isso implica saber que toda a criação faz parte da obra criadora e redentora de Deus, remetendo os humanos ao seu lugar legítimo como elos ou elementos de uma rede cósmica maior. Isso pode abrir possibilidades para a admiração e o louvor a Deus, conduzindo a viver a vida entendida como dádiva para ser vivida, em gratuidade, em confiança na presença e no amor gratuito de Deus. O cuidado com o ambiente pode e deve ser hoje uma resposta ao amor redentor de Deus. Junto com o criador, as pessoas podem ser cuidadoras e mantenedoras, ajudando a salvaguardar a dignidade de vida das gerações presentes e futuras, mantendo, assim, a esperança pelo destino redentor prefigurado na ressurreição de Cristo e firmando, como pessoas e como comunidade de fé ou de boa vontade, passos e ações de compromisso.

\section{Referências Bibliográficas}

BOFF, Leonardo. A opção terra. A solução para a terra não cai do céu. Rio de Janeiro; São Paulo: Record, 2009.

. Saber cuidar. Ética do humano, compaixão pela Terra. Petrópolis: Vozes, 1999.

BRAKEMEIER, Gottfried. Ciência ou religião: quem vai conduzir a história? São Leopoldo: Sinodal, 2006.

BULCAO, Marly. O Binômio natureza-cultura. A perspectiva de Gaston Bachelard. In: CESAR, Constança Marcondes (Ed.). Natureza, cultura e meio ambiente. Campinas: Editora Alínea, 2006, p. 27-34.

CAPRA, Fritjof. A teia da vida. Uma nova compreensão científica dos sistemas vivos. São Paulo: Cultrix, 1996.

. O Ponto de Mutação: a ciência, a sociedade e a cultura emergente. Tradução de Álvaro Cabral. São Paulo: Cultrix, 2006.

CHARDIN, T. Hino do universo; A missão sobre o mundo; Cristo na matéria; Três histórias no estilo de Benson; A potência espiritual da matéria. São Paulo: Paulus, 1994.

Coletânea Fontes e caminhos ecofeministas. São Leopoldo: Cebi, 2002.

DIAS, Genebaldo Freire. Pegada ecológica e sustentabilidade humana. São Paulo: Gaia, 2009. 
GEBARA, Ivone. Teologia ecofeminista. Ensaio para repensar o conhecimento e a religião. São Paulo: Olho dágua, 1997.

GLEISER, Marcelo. Criação imperfeita. Cosmo, vida e código da natureza. Rio de Janeiro: Record, 2009.

JONAS, Hans. O princípio responsabilidade. Rio de Janeiro: PUC; Contexto, 2006.

KÜNG, Hans. O princípio de todas as coisas. Ciências naturais e religião. Petrópolis: Vozes, 2007.

LOVELOCK, James. Gaia. Um novo olhar sobre a vida na terra. Lisboa: Edições 70, 1989, p. 27.

. As eras de Gaia. A biografia da nossa terra viva. São Paulo: Campus, 1991.

MIES, Mari; SHIVA, Vandana. Ökofeminismus: Beiträge zur Praxis und Theorie. Zürich: Rotpunkt-Verlage, 1995.

MOLTMANN, Jürgen. Ciência e sabedoria. Um diálogo entre ciência natural e teologia. São Paulo: Loyola, 2007.

. Deus na criação. Doutrina ecológica de Deus. Tradução Haroldo Reimer. Petrópolis: Vozes, 1996;

MORIN, Edgar. Ciência com consciência. Rio de Janeiro: Bertrand, 1995.

MURAD, Afonso. Aquele que passeia em nós. São Paulo: Paulinas, 2009.

REIMER, Haroldo. Bíblia e ecologia. São Paulo: Reflexão, 2010, p. 20-45. . "Mitologia e Bíblia”, em: RICHTER REIMER, Ivoni e MATOS, Keila (eds.). Mitologia e literatura sagrada. Goiânia: Editora PUC Goiás, 2009, p. 11-38.

. RICHTER REIMER, Ivoni. Tempos de graça. Jubileu e as tradições jubilares na Bíblia. São Leopoldo: Sinodal; Cebi; São Paulo: Paulus, 1999.

RICHTER REIMER, Ivoni. Terra e água na espiritualidade do movimento de Jesus. Contribuições para um mundo globalizado. Goiânia: PUC Goiás; São Leopoldo: Oikos, 2010.

RIBEIRO, Osvaldo Luiz. Vento Tempestuoso: um ensaio sobre a tradução e a interpretação de Gn 1, 2 à luz de Jr 4. Fragmentos de Cultura, Goiânia, v. 12, n. 4, p. 573-598, 2002.

SIMKINS, Ronald A. Criador e criação. A natureza na mundividência do antigo Israel. Tradução de Jaime A. Clasen. Petrópolis: Vozes, 2004.

SOUZA, Waldir. "O princípio responsabilidade" em Hans Jonas. Um desafio para a bioética numa contínua transcendência. Atualidade Teológica, Rio de Janeiro, ano XIV, n. 35, p. 172-194, 2010.

TAVARES, Sinivaldo S. Teologia da criação. Outro olhar - novas relações. Petrópolis: Vozes, 2010, p. 57-70. 


\section{Resumo}

$\mathrm{O}$ artigo busca delinear o conceito de criação na linguagem bíblica, ressaltando que se trata de um espaço sempre de novo conquistado ao caos. Este espaço de vida deve ser preservado pelo próprio Deus e pelo ser humano. Esboça também o desenvolvimento do paradigma científico moderno com suas ameaças ao ambiente, bem como o desenvolvimento de uma consciência ecológica, que também se expressa em termos de interpretação de textos bíblicos. Por fim, o artigo apresenta algumas perspectivas bíblicas de cuidado para com a criação.

Palavras-chave: Criação, Cuidado, Bíblia, Meio Ambiente, Ecologia Humana.

\section{Abstract $^{29}$}

The present article seeks to outline the concept of creation in the biblical language, emphasizing it is a space which is being conquered over and over again from chaos. That living space must be preserved by God himself and by mankind. The article also sketches the development of the modern scientific paradigm with its threats to the environment, as well as the development of an ecological conscience, which is also expressed in terms of interpretation of biblical texts. Finally, the article presents some biblical perspectives of care for creation.

Keywords: Creation, Care, Bible, Environment, Human Ecology.

Haroldo Reimer

Doutor em Teologia pela Kirchliche Hochschule Bethel, Alemanha Professor na PUC Goiás e na Universidade Estadual de Goiás Bolsista de Produtividade em Pesquisa do Conselho Nacional de Desenvolvimento Científico e Tecnológico (CNPq)

E-mail: haroldo.reimer@gmail.com

Artigo Recebido em 17/03/11

Artigo Aprovado em 05/04/11

${ }^{29}$ Agradeço a Claude Detienne a gentileza da tradução do resumo para o inglês. 